Received: November 2, 2017

\title{
Analysis of the Correlation Between Folk Music Education and Chinese Traditional Culture*
}

\author{
Ning $\mathrm{Xu}^{1}$ \\ Art Academy of Northeast Agriculture University
}

\begin{abstract}
The folk music is rich in the variety and content with a long history, and can be better preserved and inherited through folk music education. This paper, targeted at the main problems in the folk music education, analyzed the benefits of Chinese traditional culture for folk music education and the significance of the successful folk music education for further prosperity of Chinese traditional culture. The research results of this paper make up for the insufficient analysis of the correlation between folk music education and Chinese traditional culture in previous studies, and serves as a critical guide for the cultivation of students' folk music competency, inheritance and promotion of folk music, and development of Chinese traditional culture.
\end{abstract}

\section{Keywords}

Folk Music • Music Education • Traditional Culture

\footnotetext{
* This work was funded as Study of Ancient Chinese Music Education Thought and Its Contemporary Value, Project No.: 2018A002, Heilongjiang Province Art Planning Subject

${ }^{1}$ Correspondence to: Ning Xu (MA), Art Academy of Northeast Agriculture University, Harbin 150001, China. Email: xuning19810226@163.com
}

Citation: Xu, N., Analysis of the Correlation Between Folk Music Education and Chinese Traditional Culture. Educational Sciences: Theory \& Practice, 18(5), 2564-2570. http://dx.doi.org/10.12738/estp.2018.5.159 
In recent years, it has been the consensus of the public that folk music is inseparable from Chinese traditional culture. However, the research on the correlation between folk music education and Chinese traditional culture requires further study.

In the previous researches, some analyzed the importance of Chinese traditional culture to folk music education (Ho, 2003), and some studied the role of Chinese higher education in the inheritance and development of folk music (Chen-Hafteck, 2007). Some systematically elaborated on folk music and its educational history (Brand, 2003). Some proposed the establishment of the music education system under the background of traditional culture (Mori, 2002), and some focused on the specific strategy for the inheritance of Chinese traditional culture in music education (Ilari, Chen-hafteck \& Crawford, 2013). Despite frequent demonstrations of the concepts of general music education, folk music education, folk music history, Chinese traditional culture, etc. in the previous research results, there is still a lack of a systematic analysis of the relationship between folk music education and Chinese traditional culture.

In view of the deficiencies in previous research results, this paper analyzed the correlation between folk music education and Chinese traditional culture. Specifically, the promotion of Chinese traditional culture for the folk music education were elaborated in terms of understanding, inheritance, and creation of folk music; the significance of folk music education for Chinese traditional culture was analyzed from three perspectives of enhancing students' folk music competency, stimulating students' interests for traditional culture, and promoting students' recognition of traditional culture.

This paper falls into five parts, namely part 1 of introduction, part 2 of the status quo of folk music education, part 3 of the main aspects of Chinese traditional culture, part 4 of detailed analysis of the correlation between folk music education and Chinese traditional culture, and part 5 of the conclusion.

\section{Status quo of folk music education}

China is a multi-ethnic country, and various ethnic groups have produced distinctive folk music in the long history of development. So far, China's folk music of all ethnic groups contains hundreds of thousands of songs and hundreds of musical instruments (Whitcomb, Berger \& Schmidt, 2011). Typical folk songs and instruments are shown in Table 1 and Table 2, respectively.

Table 1

Typical Folk Songs

\begin{tabular}{lll}
\hline Number & Nation & \multicolumn{1}{c}{ Songs } \\
\hline 1 & Han nationality & $\begin{array}{l}\text { High mountains and rivers, The spring snow, Nichang, Shannxi opera, } \\
\text { etc. }\end{array}$ \\
\hline 2 & $\begin{array}{l}\text { Tibetan } \\
\text { nationality }\end{array}$ & Epic of king gesar, Ah zhong, Arrow song, Song of marriage, etc. \\
\hline 3 & Yi nationality & Ah shi ma, Song of graze cattle, Mother's daughter, etc. \\
\hline & $\begin{array}{l}\text { Mongolian } \\
\text { nationality }\end{array}$ & Pastoral songs, Song of yellow horse, Nostalgia, Sweetheart, etc. \\
\hline
\end{tabular}


Table 2

Category of Folk Music Instruments

\begin{tabular}{cll}
\hline Number & Instrument category & \multicolumn{1}{c}{ Examples } \\
\hline 1 & Wind instruments & Bamboo flute, Panpipe, Suona horn, Lusheng, etc. \\
\hline 2 & $\begin{array}{l}\text { Plucked stringed } \\
\text { instruments }\end{array}$ & Pipa, Moon guitar, Tamboura, Guzheng, etc. \\
\hline 3 & Percussion instruments & Wooden drum, Gong, Chimes, Bronze drum, etc. \\
\hline 4 & Bowing instruments & Erhu, Horse head string instrument, Single-string instrument, etc. \\
\hline
\end{tabular}

At first, the development of folk music relied mainly on folk inheritance. With the establishment and improvement of the modern education system, the folk music embarked on the right track of educational inheritance. However, due to external and internal factors, the development of the current folk music culture has slowed down, and the status quo of folk music education is not optimistic. In terms of the external reason, although the folk music education has always been valued by people, insufficient personnel and capital investment have made the folk music education seriously lags behind the demand of folk music culture for a period of time. The folk music of some ethnic groups has even disappeared. At the same time, the influx of foreign music culture has also a certain degree of impact on folk music education, resulting in students' low interest in folk music learning, insufficient folk music curriculum set by universities, and low attention to folk music education from the society. Internally, the folk music education witnesses old-fashioned teaching philosophy, simple and single teaching methods, and superficial cultural potential development. For the oldfashioned teaching philosophy, teachers strictly follow the syllabus, which limits the initiative of teachers to a certain extent. Under the simple and single teaching methods, students learn according to the curriculum design without enough active participation, failing to achieve mutual benefits of teaching and learning. As for the superficial cultural potential development, there are few researches on the cultural background of folk music, which deprives folk music and its education of a long-lasting future. In addition, the folk music education lacks innovative motivation and cannot keep pace with the times, which is the main internal reason for the predicament of folk music (Song, 2001).

In response to the above problems, the central and local governments of China have paid attention to the development of folk music, and aim to protect and foster the inheritance of folk music by folk music education (Du, 2006). For instance, projects are initiated with investing funds and special personnel to conduct rescue explorations on the endangered folk music; the existing folk music is preserved in the form of publications; regulations, systems, methods, and protection bases are established to provide preferential policy support for folk music; according to the characteristics of different ethnic groups, relevant authorities have established a flexible and effective folk music education mechanism, recognized the contribution of teachers in cultural protection, and encouraged students to inherit and innovate. As a result of joint efforts in all aspects, the dilemma of folk music education has been alleviated to some extent.

\section{A brief of Chinese traditional culture}

Chinese traditional culture has a long history and rich connotations. This section only makes a brief analysis of Chinese traditional culture. According to disciplines, Chinese traditional culture is divided into philosophy, 
calligraphy, painting, music, architecture, poetry, martial arts, folk customs, etc. It can be seen that music is part of Chinese traditional culture, and is inextricably linked with other categories of traditional culture (Lau, 2005; Steen, 2005). Additionally, each cultural category can be subdivided into multiple subcategories. In terms of the components, Chinese traditional culture can be classified into Han culture, Hui culture, Uygur culture, Mongolian culture, Zhuang culture and other ethnic cultures. It means that Chinese traditional culture is a unified name of the culture of all Chinese ethnic groups, and brings together the wisdom and development achievements of all ethnic groups. In line with the historical stage, Chinese traditional culture falls into different cultures at various civilization stages, such as pre-Qin culture, Han-Tang culture, Song culture, Ming and Qing culture. Geographically, Chinese traditional culture can be divided into the Yangtze River Basin culture, the Yellow River Basin culture, and the south Fujian culture, etc.

\section{Analysis of Correlation between folk music and Chinese traditional culture}

Folk music education and Chinese traditional culture complement and cause each other. Chinese traditional culture is an irreplaceable promoter of folk music education, while folk music education has an extraordinary significance for Chinese traditional culture.

\section{Promotion of Chinese traditional culture for folk music}

Chinese traditional culture promotes folk music education mainly the following three aspects.

Advance the understanding of folk music. Folk music is one of the carriers of Chinese traditional culture, and also part of Chinese traditional culture. The rich accumulation of traditional culture is undoubtedly very helpful in understanding folk music. For example, due to the late appearance of characters in certain ethnic groups, the historical developments, major events, customs, emotional expressions, and value orientations of the ethnic group are often recorded in music and passed down through generations to educate the public. When students understand the folk culture, they will have a deeper understanding of the message that folk music intends to convey. In addition, in recent years, more and more students have come into contact with foreign music culture, broadening their horizons and improving their appreciation. On this basis, through the study of Chinese traditional culture, students can compare the foreign culture and Chinese traditional culture. After the deep thinking, they will undoubtedly more profoundly understand the folk music, its characteristics, and even its shortcomings.

Advance the inheritance of folk music. By deepening the understanding of Chinese traditional culture, we can deeply study the theoretical research of folk music, break the existing restrictions, update the existing concepts, and then propose a more suitable inheritance method and form of folk music. For example, during the teaching of folk music, based on the traditional cultural knowledge that students already know, teachers can propose more targeted curriculum design, offer more background information, increase the effective interaction between teachers and students, and add more vivid social practices. The folk music education based on Chinese traditional culture avoids the rigid formalized education and focuses more on the learning effect of students. By improving the learning effect, broadening the horizons, guiding social practice, and encouraging active 
participation of students, teachers are helping students to lay a good foundation in the folk music innovation while promoting the effective inheritance of basic knowledge of folk music.

Advance the creation of folk music. Chinese traditional culture with profound essence and diverse manifestations is the best "soil" for the creation and innovation of folk music content. The creation of folk music should not only be regarded as the change in melody, the improvement of musical instruments, the innovation of performance, but more as an effective way to develop and express traditional culture. Therefore, learning and mastering Chinese traditional culture as the times goes forward is the source of inspiration for folk music creation. The accumulation of Chinese traditional culture will also have an impact on the creator's spiritual temperament and creative level. The creators with higher levels of traditional cultural accumulation are more familiar with the customs, music, and culture of each ethnic group, and are better able to comprehend by analogy to more accurately express the true feelings. On the contrary, the creators with lower levels of traditional cultural accumulation are lacking in the knowledge of each ethnic group. Without comprehensive information and weak integration ability, they cannot generate high-level musical works.

\section{The importance of folk music education for Chinese traditional culture}

The importance of folk music education for Chinese traditional culture mainly includes the following three aspects.

Enhance students' folk music competency. The systematic folk music education can effectively improve students' folk music competency. Folk music has its own different backgrounds. In the process of development, it has gradually formed a distinct style of melody and singing. These large number of excellent folk music carrying many cultural elements, while learning basic music knowledge and different performance techniques, will undoubtedly allow students to experience the charm of different music, learn the way different music expresses emotions, comprehend the creative methods of different music, exercise the ability to appreciate music, cultivate healthy music aesthetic taste, and thus enhance the students' folk music competency in an allround way. In addition, folk music is compatible with Chinese traditional culture and absorbs good points for innovation. In other words, folk music is traditional but not old-fashioned. At the right timing, folk music will innovate on the basis of integrating elements of other music. This openness will positively promote student's folk music competency, and will also have a positive effect on students' accurate understanding of the connotations of Chinese traditional culture.

Inspire students' interest in ethnic culture. Folk music, accompanying the emergence, growth and development of an ethnic group, often carries the history, thought, culture and spiritual temperament of this nation. The educational process of folk music is also the cultural inheritance process of this nation. While exploring the origin of folk music, students often have a strong interest in the culture of this nation. Studies have shown that folk music education plays an irreplaceable role in stimulating students' interest in ethnic culture. Taking musical instruments as an example, Chinese folk music is played often by traditional Chinese musical instruments (such as erhu, suona, guzheng, etc.) that often embody the cultural wisdom of different ethnic groups. While performing beautiful melody, these traditional instruments also express the culture behind. With deep research on traditional musical instruments, students, consciously or unconsciously, will touch knowledge about ethnic culture. 
Promote students' recognition of traditional culture. One of the important purposes of folk music education is to enhance students' recognition of Chinese traditional culture. Chinese traditional culture is the common fruits of China's fifty-six ethic groups, with broad geographical and temporal dimensions. Chinese traditional culture is also a fusion of various ethnic cultures colliding with and learning from each other, with the content unified and inseparable. While learning different folk music, students can often integrate the different elements based on active thinking, and deeply understand the internal unity of various ethnic cultures in history, thought, art, etc., thus further deepening the recognition of the values advocated by Chinese traditional culture. The exchange of ideas between students under different folk music backgrounds will also lead to artistic resonance based on Chinese traditional culture, which will produce more powerful unity and Chinese national pride. Only music creators with strong national consciousness and patriotic enthusiasm can create a masterpiece that is more in line with the requirements of traditional culture and more acceptable to the world.

\section{Conclusion}

The correlation between folk music education and Chinese traditional culture is a complex subject that needs to be reviewed frequently. This paper first analyzed the main problems facing the folk music education, then briefly described the main aspects of Chinese traditional culture, and finally elaborated the correlation between folk music education and Chinese traditional culture from two perspectives of the promotion of folk music education for Chinese traditional culture and the importance of folk music education for Chinese traditional culture. The research results of this paper, through comprehensive analysis of the correlation between folk music education and Chinese traditional culture, make up for the deficiencies in the analysis of the correlation between folk music education and Chinese traditional culture in previous studies, and provide a solid theoretical basis for the ways to cultivate students' folk music competency, inherit and promote folk music, and develop Chinese traditional culture at current stage of folk music education, which is of certain guiding significance for the present folk music education.

\section{References}

Brand, M. (2003). Dragons in the music classroom: Political and philosophical subtexts in Chinese school music textbooks. Bulletin of the Council for Research in Music Education, 35(158), 72-80. http://dx.doi.org/ $10.2307 / 3250552$

Chen-Hafteck, L. (2007). Contextual analyses of children's responses to an integrated Chinese music and culture experience. Music Education Research, 9(3), 337-353. http://dx.doi.org/10.1080/14613800701587688

Du, Y. X. (2006). Developing national traditional culture. Journal of Zhejiang Vocational Academy of Art, 4(1), 97-101. http://10.15965/j.cnki.zjys.2006.01.013 
Ho, W. C. (2003). Westernization and social transformations in Chinese music education, 1895-1949. History of Education, 32(3), 289-301. http://dx.doi.org/10.1080/00467600304145

Ilari, B., Chen-hafteck, L., \& Crawford, L. (2013). Singing and cultural understanding: A music education perspective. International Journal of Music Education, 31(2), 202-216. http://dx.doi.org/ $10.1177 / 0255761413487281$

Lau, W. T. (2005). Twentieth-century school music literature in china: A departure from tradition. Journal of Historical Research in Music Education, 27(1), 33-48. http://hdl.handle.net/2260.2/2327

Mori, B. L. R. (2002). Education in traditional china: A history (review). China Review International, 9(2), 478-481. http://dx.doi.org/10.1353/cri.2003.0107

Song, T. Z. (2001). On historical viewpoint of native musical education based upon Chinese culture. Journal of Guizhou University (Art Edition), 15(2), 45-48. http://10.15958/j.cnki.gdxbysb.2001.02.010

Steen, S. (2005). Yellowface: creating the chinese in american popular music and performance, 1850-1920s, by Krystyn Moon; cold war orientalism: Asia in the middlebrow imagination, 1945-1961, by Christina Klein. Theatre Journal, 57(3), 529-531. http://dx.doi.org/10.1353/tj.2005.0122

Whitcomb, R., Berger, L. M., Schmidt, C. (2011). A general music experience in china: Reflections and lesson ideas. General Music Today, 25(1), 14-18. http://dx.doi.org/ 10.1177/1048371310396482 